\title{
Saúde, Corpo e Sociedade
}

\author{
Alicia Navarro de Souza e Jacqueline Pitanguy (orgs.), \\ Editora da UFRJ, 2006
}

Maria Tavares Cavalcanti

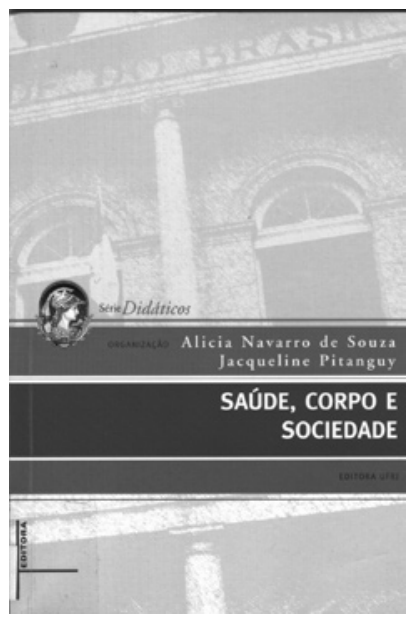

O livro Saúde, Corpo e Sociedade organizado pela professora Alícia Navarro de Souza da Faculdade de Medicina da Universidade Federal do Rio de Janeiro (UFRJ) e pela cientista política Jacqueline Pitanguy, diretora da ONG Cidadania, Estudos, Pesquisa, Informação, Ação (CEPIA), apresenta no dizer de suas organizadoras "um curso que, há dez anos, cumpre o desafio de problematizar a ideológica naturalização do saber e da prática social da medicina". Este curso, ministrado pela Faculdade de Medicina da UFRJ como uma disciplina eletiva oferecida aos diversos cursos da área da saúde, foi iniciativa do Prof. Rodolpho Rocco, Professor Titular de Prepedêutica Clínica, que em 1996 instituiu a colaboração entre a CEPIA, ONG que desenvolve projetos nas áreas de saúde e violência e a universidade na co-coordenação do curso. O objetivo do curso é discutir a ausência, na formação acadêmica, de uma conexão mais sistemática entre medicina e sociedade, e assim despertar a consciência dos estudantes sobre variáveis sociais, políticas, econômicas e culturais que incidem sobre a abordagem médica da saúde e da enfermidade. Para tal são convidados professores e profissionais que estejam desenvolvendo trabalhos de pesquisa e de reflexão teórica sobre o tema em seus mais diversos aspectos. A divisão do livro corresponde aos quatro módulos em que se organiza o curso, a saber: Sobre a Produção do Conhecimento nas Ciências da Saúde; Saberes e Práticas de Saúde - Reflexões sobre a Clínica; Corpo, Sexualidade, Violência e Práticas em Saúde; Saúde e Sociedade.

Na primeira parte, Sobre a Produção do Conhecimento nas Ciências da Saúde, são apresentados quatro artigos de cunho epistemológico e metodológico. O primeiro do prof. Alberto Oliva - Cabe ainda invocar o método científico universal? - aponta para o descrédito da filosofia da ciência ao final do século XX com a tese didaticamente expressa por Pearson de que o "método científico é um e o mesmo em todos os domínios e que o método é o método para todas as mentes logicamente treinadas" (p.24), apesar disso "predomina ainda hoje entre os praticantes da ciência voltada para fins práticos a visão de que os fatos formam e julgam as teorias" (p.43). Esta é uma visão "sedutoramente simplista" e que "mascara o aspecto fundamental de que todo o empreendimento científico envolve, já no ponto de partida, a construção de teorias heuristicamente desbravadoras e não o empilhamento de fatos com o fito de meticulosamente generalizá-los" (idem). A conclusão de Oliva é de que "a ciência ainda está em busca de um método que mereça ser visto como encarnação universal de sua racionalidade" (ibidem) e que "a única certeza que podemos ter é a de que podemos nos desvencilhar dos erros, mas jamais ter a certeza de que chegamos a uma verdade" (p.44). O segundo artigo desta primeira parte é do Pesquisador Flavio Coelho Edler que discute as idéias desenvolvidas por Thomas Kuhn a respeito da função dos paradigmas na atividade científica. Ainda neste primeiro módulo a médica Elvira Maciel analisa aspectos epistemológicos e éticos da pesquisa clínica. Levando-se em conta que "talvez a medicina não se defina como uma ciência, uma vez que é, fundamentalmente uma técnica de restauração da saúde, mas é um domínio de cientificidade, um campo de aplicação de diversas ciências que the conferem legitimidade" (p.69) como pensar a pesquisa clínica e sobretudo a sua aplicação no dia-a-dia do médico? Por fim, temos a professora Alicia 
Navarro de Souza abordando a pesquisa qualitativa em saúde, as críticas que esse método de pesquisa recebe, como sendo uma "coisa menor", "menos científica", mas, no entanto, o seu lugar fundamental tendo em vista que "a medicina é uma prática social que se apóia nas ciências biológicas e na epidemiologia para o conhecimento das doenças e, crescentemente, nas ciências humanas e sociais para o conhecimento dos sujeitos implicados nessa prática" (p.75). Pois, se "a força da pesquisa quantitativa se esteia na reprodutibilidade/confiabilidade (reliability), a força da pesquisa qualitativa se esteia na validade (validity), isto é, na profundidade do entendimento do fenômeno em questão, na sua proximidade à verdade" (p.77).

Na segunda parte do livro - Saberes e Práticas de Saúde: reflexão sobre a clínica - temos dois artigos. O primeiro do Prof. Benilton Bezerra Jr. traz à cena a discussão sobre o normal e o patológico, apresentando e reatualizando as idéias de Georges Canguilhem em seu livro fundamental para qualquer estudante de medicina - O normal e o patológico, escrito em 1943. Para Canguilhem, nas palavras de Bezerra Jr. "só é possível delimitar de forma consistente a fronteira entre o normal e o patológico quando se deixam de lado os critérios meramente objetivos e se colocam no centro da reflexão a mudança de qualidade, a alteração do valor vital que a doença impõe e que o indivíduo reconhece como limitação à sua existência" (p.95). Ou ainda, "tomar o normal como normativo implica, assim, definir o patológico não como desvio em relação a um padrão objetivamente definido, mas como expressão de uma potência normativa constrangida, a uma resposta criativa, mas "infeliz", não tão bem-sucedida quanto à norma saudável, às injunções da vida no meio em que o ser vivo se encontra" (p.101). As conseqüências para a prática médica são decisivas "para fins da saúde ou da doença, indivíduo e meio não podem ser considerados isoladamente" (p.103), além disso, "a experiência do sofrimento vem para o centro da terapêutica" (p. 106) - "contra o objetivismo reinante na medicina e na cultura [Canguilhem] não nos deixa esquecer que, em matéria de sofrimento, é o indivíduo quem deve ter a última palavra" (p.108). O segundo artigo desse módulo traz a pesquisa realizada pela médica Rachel Aisengart Menezes com os profissionais de saúde de um CTI, buscando conhecer em que se baseavam as decisões médicas referentes à doença, ao sofrimento, à vida e à morte dos pacientes. O processo decisório é o ponto para o qual convergem todas as tensões presentes no campo da prática médica, "competência-cuidado", objetividade-subjetividade", "racionalidade-experiência", "saber-sentir" etc. (p.114), uma vez que "somente o saber e a competência não dão conta da amplitude do exercício da prática médica, pois a experiência, o sentir e a subjetividade do médico também são extremamente relevantes no atendimento ao doente" (idem).

A terceira parte do livro - Corpo, sexualidade e práticas em saúde - apresenta três artigos. O primeiro do Prof. Jurandir Freire Costa - A medicina como projeto social: controle dos corpos e sexos - defende de forma contundente a idéia de que "a natureza fala a língua que a ela atribuímos" (p.140) e que, portanto, temos uma responsabilidade com as escolhas e direções dos progressos tecnológicos na área médica - "quanto mais resolutiva for a tecnologia médica, melhor será para todos nós, mas qualquer que seja o progresso alcançado, ele tem de estar subordinado ao credo moral básico de nossa cultura: respeito à vida, à liberdade, ao direito de cada um buscar sua felicidade" (p.143). A ciência "pura" não existe e "também faz parte do espírito científico saber o que nos leva a colocar certas perguntas e buscar certas respostas" (idem). Jacqueline Pitanguy em seu artigo sobre Gênero, violência e saúde argumenta de forma semelhante ao trazer à cena da discussão a questão da violência de gênero e sua invisibilidade. "Se nos perguntarmos por que ainda persiste uma relativa invisibilidade da violência de gênero, a resposta não está no campo que identificamos como violência propriamente dita, como a agressão, o estupro, o assassinato, mas na situação e na inserção política, social, econômica, cultural da mulher na sociedade e no imaginário social sobre o feminino e sobre as relações de gênero" (p.147). A violência ou o campo da violência se constitui e se expressa dentro da dinâmica das relações sociais e, portanto, pode modificar-se a partir da luta política. Em um tempo em que a política e suas práticas 
andam tão desacreditadas entre nós, o artigo de Pitanguy tem o mérito de demonstrar o quanto a luta política das minorias e dos direitos humanos tem podido contribuir para a modificação, ainda que pequena, deste quadro de invisibilidade. Em seguida a Profa. Fabíola Rohden enfoca a sexualidade e o gênero na medicina, demonstrando o quanto "sexo, gênero e sexualidade são aspectos que intervêm de forma fundamental na prática e no conhecimento médicos. Para tal, faz uma exposição histórica do interesse médico sobre a mulher e a reprodução e do surgimento da ginecologia, que nos confirma sobejamente a tese defendida em quase todos os artigos do livro, a saber, o quanto o connhecimento e a prática médica são indissolúveis dos contextos histórico, social, econômico, cultural e político em que se encontram.

A quarta parte do livro - Saúde e Sociedade - traz inicialmente um artigo da Profa. Jane Russo - Do corpo-objeto ao corpo-pessoa: desnaturalização de um pressuposto médico - que problematiza o fato de o aluno da faculdade de medicina entrar em contato inicialmente no ciclo básico com um corpo objeto, "coisificado", fragmentado, o que faz que ao se deparar com o doente a tratar, o "corpo-pessoa", na clínica, o choque seja enorme. Não se trata, no dizer da própria pesquisadora, de criar uma hierarquia entre os "corpos", mas de argumentar a favor de sua inevitável articulação. Em seguida a Profa. Madel Terezinha Luz discorre sobre biomedicina e racionalidade científica no ensino contemporâneo da área da saúde, levantando em parte essa mesma problemática - "quando o profissional médico - e não o simples pesquisador de doenças - está frente a frente com um sujeito sofredor, fica evidente, para ele, que a lógica laboratorial da doença perde sentido diante do "'encontro'" com o doente" (p. 197). "Para o cientista o importante é diagnosticar a doença e, para o terapeuta, o importante é tratar o doente" (p.198). Uma tensão, portanto, se estabelece. Não existe mais na atual complexidade dos hospitais universitários lugar para a transmissão da arte da medicina de mestre para discípulo. A tecnologia se impõe e muitas vezes a terapêutica, o tratar, é deixado em segundo plano. O Prof. Pedro Gabriel Godinho Delgado coloca em cena em seu artigo a questão da cidadania e da saúde mental, mostrando o quanto a Justiça ainda terá que se tornar mais flexível e capaz de observar as particularidades de cada situação quando se trata da cidadania dos doentes mentais, que se expressa na Justiça através dos processos de interdição e curatela. O louco continua sendo visto pela Justiça como alguém incapaz para os atos da vida civil, e apenas uma luta política, conforme defendido também por Jacqueline Pitanguy ao discutir os direitos das mulheres, poderá modificar essa situação e dar ao louco um lugar menos estigmatizado em nossa sociedade, luta que se inicia na própria clínica com os doentes mentais. Por fim, temos a enfermeira Ruth Floresta de Mesquita, que apresenta a implantação de Serviços de Atendimento em Saúde à Mulher Vítima de Violência Sexual - a experiência da cidade do Rio de Janeiro.

Este é o panorama geral do livro. Advindo de uma disciplina ministrada aos alunos da área da saúde da UFRJ, nada melhor para avaliar a sua importância do que dar a palavra aos próprios alunos, como fizeram as organizadoras do livro. São os alunos, que em consonância com as discussões apresentadas ao longo do livro, escrevem: "Portanto, os médicos modernos acabam por não ter uma visão global do paciente, nem como ser biológico nem, muito menos, como ser social. De certa forma, é essa deficiência que procuramos amenizar quando nos interessamos pela disciplina eletiva Saúde, Corpo e Sociedade. Não concordamos com esse distanciamento e fragmentação, que não contribuem para a atuação do médico frente a seu paciente, na medida em que dificulta a visualização do indivíduo como um ser completo, não só biológico, que interage com tudo o que está a sua volta".

Só nos resta parabenizar a editora da UFRJ e as organizadoras do livro pela iniciativa de sua publicação que proporcionará a alunos e estudiosos de outras faculdades e universidades entrar em contato com essa discussão tão fundamental para a formação dos profissionais da saúde nos tempos atuais. 